\title{
A completely reusable aerospace system based on subsonic carrier with the return of the first stages to the starting point
}

\author{
V. I. Buzuluk' ${ }^{1}$ S. M. Mikhalyov ${ }^{1}$ D
}

Received: 18 June 2019 / Revised: 7 November 2020 / Accepted: 29 December 2020 / Published online: 23 February 2021

(c) The Author(s) 2021

\begin{abstract}
The concept of aerospace system based on air launch from subsonic twin-fuselage aircraft and the rocket launch into orbit is investigated. The scheme of aerospace system trajectory providing a return to the starting point both of the carrier and the first rocket stage with liquid-fuel motors is proposed. It was shown that the use of subsonic carrier as a launching platform of the rocket system increases the payload mass by $1.2 \%$ of the rocket segment MTOW as compared to autonomous ground take-off. The comparative analysis of three versions of carrier aircraft and three fuel options at the first rocket stage was carried out. Analysis showed that compared to kerosene variant the hydrogen hypersonic booster makes it possible to significantly increase the payload mass while the launching costs stay the same.
\end{abstract}

Keywords Cruise rocket stage $\cdot$ Optimization of design parameters $\cdot$ Completely reusable orbital injection system $\cdot$ Rocket system $\cdot$ Configuration design

\section{Introduction}

According to the developed strategy for the policy of Russian space activities until 2030 and for the future, it is planned to ensure the world level of Russian cosmonautics [1]. In this document, it is noted that one of the breakthrough technologies is the implementation of reusable launch systems. This is due to the fact that Russia's space activities are expected to significantly increase (by an order of magnitude or more) cargo traffic to earth orbit.

Work on creating reusable space transport systems is underway both in Russia and abroad. Such systems are designed to provide a significant reduction in the specific cost of injection compared to existing expendable rockets. Energiya-Buran [2], Space Shuttle [3], MAKS project [4], and MRKS-1 [5] were a significant step towards the creation of reusable rocket system.

In recent years, TsAGI has been carrying out research to determine the rational configuration of a completely reusable

V. I. Buzuluk

vbuzuluk@yandex.ru

S. M. Mikhalyov

semyon.mikhalyov@tsagi.ru

1 TsAGI, 1, Zhukovsky Street, Zhukovsky Town, Moscow region, Russia aerospace system of horizontal start designed to launch the payloads and crews into the orbit and return them to Earth. The aerospace system can also be used for fast transcontinental flights and for space tourism [6-10].

The purpose of this work is to illustrate the application of a methodology for multidisciplinary calculation and selection of optimal parameters at the stage of the conceptual design of a perspective reusable aerospace system designed to solve transport problems of launching into orbit.

\section{Justification of the aerospace system concept}

Initially, the aerospace system was studied in TsAGI on the basis of the Il-76 carrier and a single-stage shuttle with liquid rocket engine (Fig. 1). It is shown that such a system can shorten the duration of intercontinental flights up to 1-1, $5 \mathrm{~h}$. At that, the shuttle should accelerate nearly to orbital velocity (by $100-200 \mathrm{~m} / \mathrm{s}$ less than orbital velocity), then perform a space flight at altitudes of more than $100 \mathrm{~km}$ and decelerate in reentry environment with subsequent landing on the airfield. The shuttle MTOW is about 50 tons. Since the required fuel capacity of such a vehicle reaches $85 \%$, the payload relative mass does not exceed $0.5 \%$ of the shuttle MTOW. 


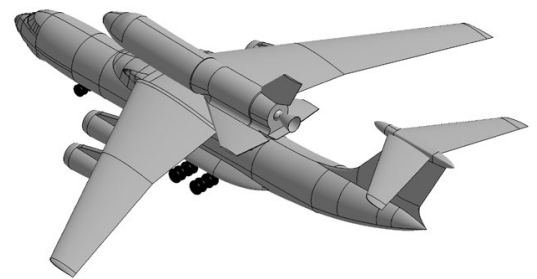

Fig. 1 Aerospace system for intercontinental flights based on Il-76 carrier

A suborbital hypersonic aircraft with a liquid rocket engine and a wide-range scramjet was also studied (Fig. 2). The launching mass of the vehicle is 100 tons. It takes off using liquid rocket engine and accelerates to the speed when the wide-range scramjet becomes effective. At the final stage of acceleration, the rocket engine is also used, as a result the suborbital hypersonic aircraft reaches the flight Mach numbers of 20-21, then it glides with inoperative engines at maximum $C_{\mathrm{L}} / \mathrm{C}_{\mathrm{D}}$ mode (2.8-3.0) providing a total flight range up to $15,000-18,000 \mathrm{~km}$.

In $[11,12]$ it is shown that the travelling time of suborbital hypersonic aircraft during a flight to a range of $16,500 \mathrm{~km}$ is about $3 \mathrm{~h}$. In this case, the required fuel mass is largely determined by the level of thrust loss in the wide-range scramjet track. Thus, with a decrease in nozzle thrust losses of up to $3 \%$, the required fuel capacity can be reduced to $72 \%$ due to an increase in the maximum Mach number of the scramjet operation to $\sim 15$. If such a vehicle is implemented, its payload relative mass will be about $1.4 \%$.

Alternative versions of the suborbital hypersonic vehicle were considered:

- in case of using a nuclear rocket engine with a specific impulse of $930 \mathrm{~s}$ (the propulsive mass is hydrogen), the required fuel capacity can be reduced to $61 \%$ of the vehicle MTOW, however, the payload mass remains at the level of $1.4 \%$ due to a considerable proportion of radiation protection in the vehicle weight balance;

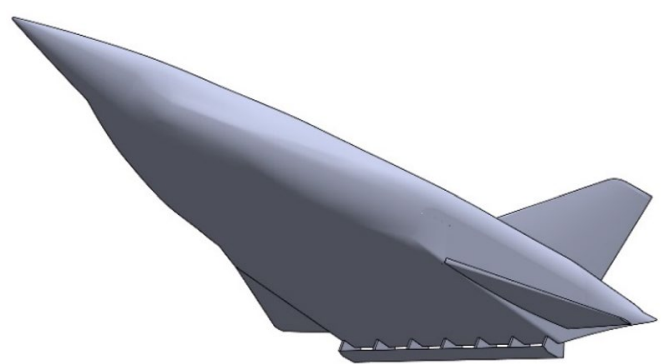

Fig. 2 Suborbital hypersonic vehicle of acceleration-gliding type with wide-range scramjet
- in case of launching a suborbital hypersonic vehicle with wide-range hypersonic scramjet at Mach number $M=7$ (the first stage is a booster plane with rocket engine) the required fuel capacity can be reduced to $58 \%$ (with a high proportion of liquid hydrogen). In this case, the payload mass can be increased to $11 \%$ of the vehicle MTOW, however, a heavy booster is also needed.

The above examples show that the single-stage injection requires a substantial onboard fuel supply, which makes the creation of such vehicles practically impossible, or there is a very high risk of failure. In this regard, a two-stage rocket system with a liquid rocket engine was considered in more detail. Different variants of take-off were studied:

- classic take-off from airfield (using turbojet, rocket, or rocket-ramjet engines);

- take-off using a cable system (the first stage tows a second stage);

- start by means of a ground booster device (accelerating rocket cart);

- take-off with under-filled fuel tanks with their subsequent refueling in the air from fueler.

Different variants for connecting rocket stages were also considered:

- the second stage is within the first stage;

- the second stage is behind the first stage (acceleration by means of cable system);

- the second stage is above the first stage.

The comparative analysis shows that the most rational is a two-stage rocket system, with a parallel connection of stages (the second stage is located above the first stage) which independently takes off from airfield (Fig. 3).

The first stage is a hypersonic booster with a rocket engine, the second stage is a shuttle with rocket engine; the fuel-liquid oxygen and hydrogen. The study of optimal flight modes showed that separation of stages should occur

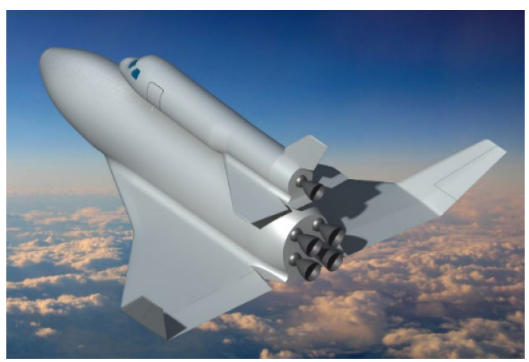

Fig. 3 Two-stage rocket system of horizontal start with a liquid rocket engine 
at Mach number of 8-9 at an altitude of about $100 \mathrm{~km}$. After the aerospace system detachment, the booster makes a horizontal landing on the intermediate airfield in air route area. The shuttle moves as in the previous variants.

A characteristic feature of the rocket system in case of intercontinental flight is the alternation of high and zero g-force. In this regard, the flight analysis takes into account the restrictions on longitudinal and normal g-force (not more than 1.8). Such a restriction leads to a corresponding decrease in the energy-mass characteristics of rocket system.

The two-stage concept of a rocket system with liquid-propellant motors provides minimum time for intercontinental distances - the flight time for a range of 16,000-17,000 km is about $50 \mathrm{~min}$. However, the rocket system with a liquid rocket engine has a number of drawbacks:

- the effect of rocket engine jets on the runway;

- significant loss of characteristic velocity in case of launch azimuth and runway direction mismatch;

- impossible to ensure parallax during the injection.

In addition, there is a considerable rocket system performance degradation when it is necessary to return the first stage to the launching point (for example, when the flight route of rocket system runs over the seas and oceans).

In this connection, the final version of aerospace system was proposed, based on the air start from a twin-fuselage subsonic carrier. Such a solution is well-known. For example, in NPO "Molniya" various concepts of aerospace system based on perspective twin-fuselage aircraft [13] were considered and the design of a heavy perspective twin-fuselage carrier "Hercules" with a MTOW of 900 tons was studied.

At present, the privately owned US company Stratolaunch Systems is developing the aerospace system based on a new perspective twin-fuselage carrier (Fig. 4) [14]. The subsonic carrier is claimed to be the largest aircraft in the world. Its takeoff weight will be 544 tons; the length $-65.5 \mathrm{~m}$; the wingspan $-116 \mathrm{~m}$. The aircraft will be equipped with six

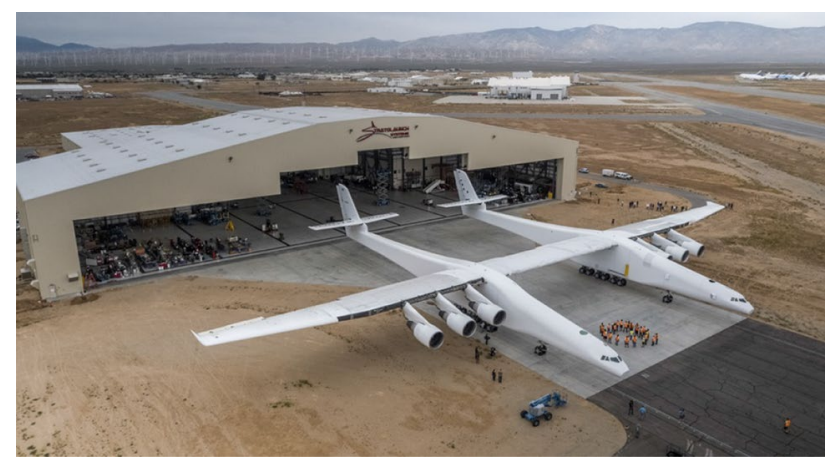

Fig. 4 Stratolaunch aerospace system (USA project) engines from Boeing - 747 and will require a runway of $3.7 \mathrm{~km}$ long for take-off and landing.

Stratolaunch aerospace system is intended for orbital injection of various cargoes and piloted spacecraft with a mass of up to 6.1 tons. A 222-ton staged carrier rocket starting from an airplane at an altitude of $9.1 \mathrm{~km}$ will be used for orbital injection.

In this paper, the air-launched rocket system is completely reusable, two-staged, with a tandem connection of stages. The first stage is a hypersonic booster, the second stage is a shuttle with a liquid-propellant engine (Fig. 5). MTOW of the rocket system in all variants is assumed to be fixed and equal to 120 tons. The parameters of the rocket system lifting surfaces and landing gear are selected from the condition of their return flight and horizontal landing on the airfield, which significantly reduces the rocket system dry mass as compared to the version of autonomous launch. The rocket system suspension to the subsonic carrier is underneath the center-wing section. In Fig. 6 the aerospace system is shown with one of the possible versions of twin-fuselage carrier. Investigations of such aerospace system began in TsAGI in 2014 [7].

It is shown that the use of subsonic carrier as a launching platform of the rocket system increases the payload mass by $1.2 \%$ of the rocket segment MTOW as compared to

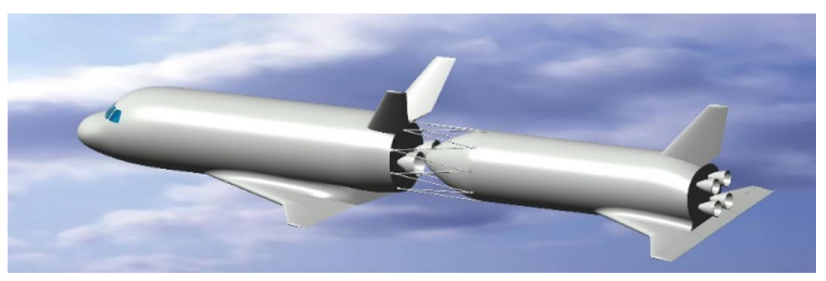

Fig. 5 Two-stage rocket system with a tandem connection of stages

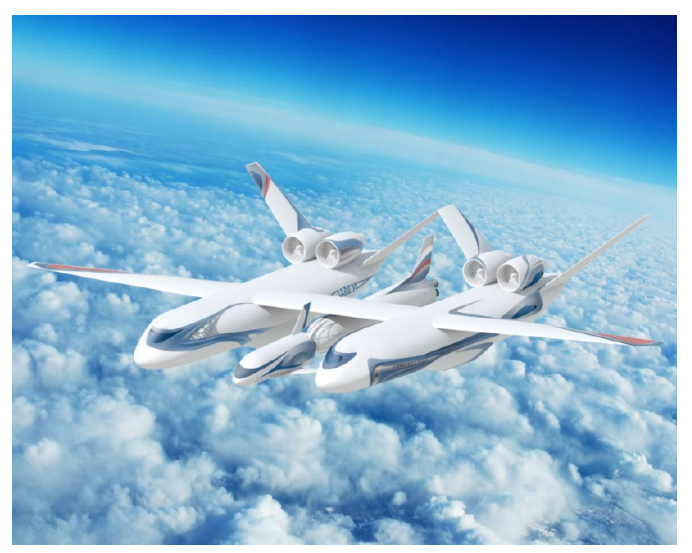

Fig. 6 Completely reusable aerospace system based on twin-fuselage carrier plane (one of the carrier plane variants) 
aerospace system of autonomous horizontal ground take-off, which is consistent with previous studies in this field [15].

The aerospace system with the subsonic carrier has all the advantages of aircraft take-off and the lower suspension of the rocket system makes the stage docking and landing of the crew and passengers easy and operationally convenient. The technical feasibility of this concept is ensured by the available scientific, technical, experimental and operational backlog in aeronautics and astronautics (Space Shuttle, "Energiya-Buran", MAKS-OS, MRKS 1 projects, etc.)

\subsection{Ensuring the return of the first stages of aerospace system to the starting point}

In this case, one of the problematic issues of ensuring the reusability of the rocket system is the return of the first rocket stage to the starting point. Preliminary estimates of the hypersonic booster flight path showed that its total range first with rocket system, and then in a dynamic motion and in the deceleration phase is $1500-2000 \mathrm{~km}$. There are different ways to return the hypersonic booster to starting airfield.

(1) Thus, for example, the hypersonic booster can be equipped with a jet engine with appropriate fuel supply. After deceleration in the atmosphere to subsonic speed, the hypersonic booster makes a $180^{\circ}$ turn and after the engine starting commits a cruise flight to aerospace system take-off airfield. Such a return technique is provided, for example, for cruise rocket units of the first stage of the MRKS-1 reusable system of vertical start.

At the same time, since the hypersonic booster is designed for hypersonic flight speeds, its subsonic quality is low and, therefore, the cruising range parameter will be significantly lower as compared to subsonic aircraft. The weight costs associated with the increase in dry mass and extra fuel will lead to a significant reduction in the shuttle payload mass, which is unacceptable.

(2) Instead of installing the jet engine it is possible to reuse the hypersonic booster rocket engine. In this case, the hypersonic booster also decelerates in the atmosphere, makes a $180^{\circ}$ turn and then accelerates again using the rocket engine to the speed necessary to ensure the required gliding range. In this case, the required relative fuel supply is almost the same as in the case of a normal acceleration to the speed of shuttle separation. The weight costs associated with an additional increase in fuel will also lead to a significant reduction in payload mass of the shuttle.

(3) To ensure the hypersonic booster return it is possible to use a sufficiently high energy potential of the twinfuselage subsonic carrier. Preliminary flight of the aerospace system in the direction opposite to the launching direction of the rocket system allows for moving the rocket system launching point to the required distance in relation to the takeoff airfield. As a result, the rocket system characteristics virtually do not change, and the required fuel capacity of the shuttle increases so as to provide a flight range of about $3000 \mathrm{~km}$. In this case, the twin-fuselage subsonic carrier configuration design should take into account the need for such a flight range along with the rocket system.

Finally, the last version of hypersonic booster return to the starting airfield was adopted for a more detailed study. The flight path of aerospace system assembly consists of four main sections (Fig. 7):

- airfield take-off and flight to the launching point of the rocket system;

- a $180^{\circ}$ turn;

- additional acceleration of aerospace system, "steep climb" maneuver and the rocket system start;

- return flight to the airfield of subsonic carrier or aerospace system take-off (in case of mission cancellation)

\section{Carrier airplane}

Three versions of the carrier airplane were considered:

- twin-fuselage carrier based on IL-76 transport airplane (Fig. 8);
Fig. 7 Scheme of aerospace system assembly and the booster return flight when launching the rocket system into orbit

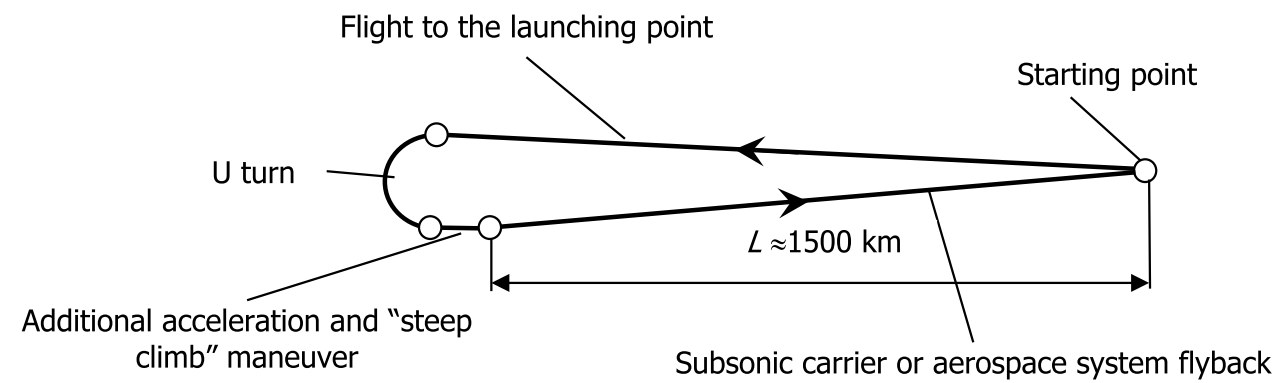




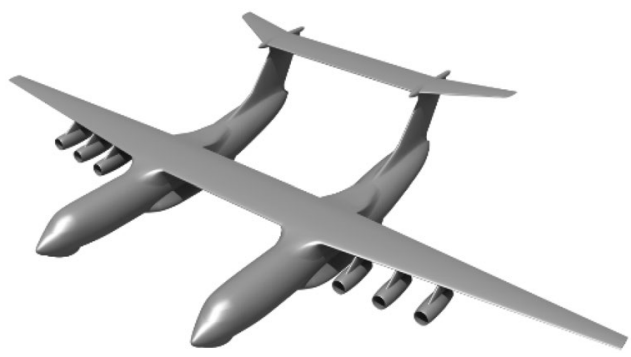

Fig. 8 Twin-fuselage subsonic carrier based on Il-76 airplane

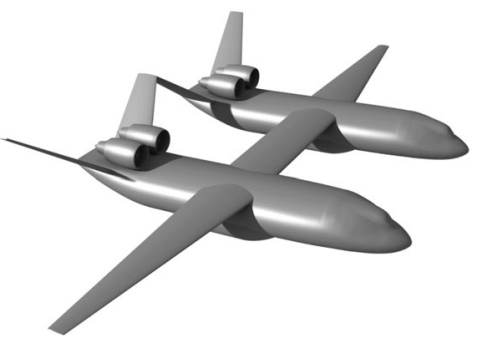

Fig. 9 Twin-fuselage subsonic carrier based on M-60 type airplane

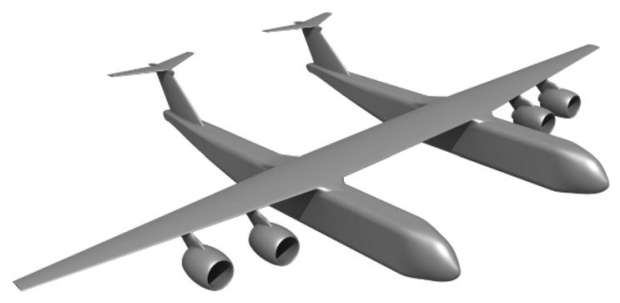

Fig. 10 Perspective twin-fuselage subsonic carrier

- twin-fuselage carrier based on perspective airplane of the M-60 type (Design Bureau by V. M. Myasishchev) (Fig. 9);

- perspective twin-fuselage airplane (Fig. 10).

To calculate the weight characteristics, a computational complex developed by the author and some elements of an automated settlement-dialogue system (ARDIS) were used [16].

A comparison of the three variants of carrier aircraft showed that the best option is the use of a perspective twin-fuselage aircraft. In this case, due to the smaller total fuselage mid-section area and lower dry mass the largest cruising range is provided (by $\sim 25 \%$ more than in a version of the aerospace system with a twin-fuselage carrier), which ensures operational flight radius of $1500 \mathrm{~km}$.

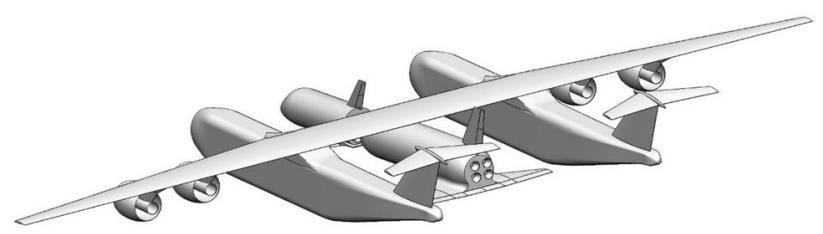

Fig. 11 Aerospace system based on perspective twin-fuselage subsonic carrier

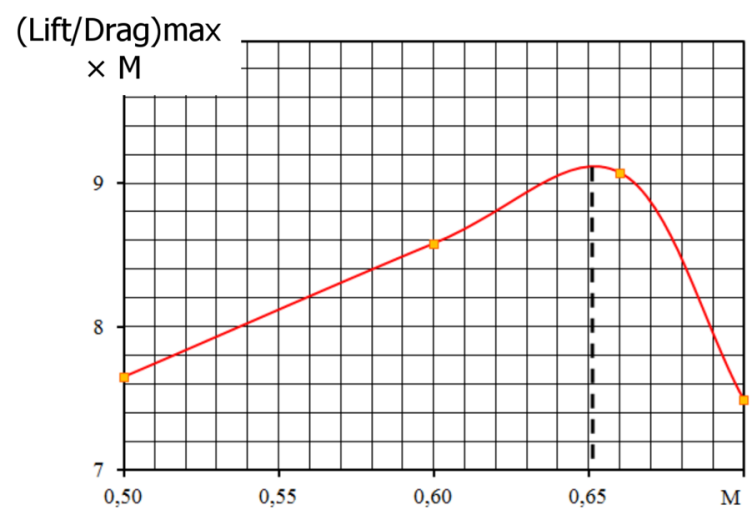

Fig. 12 Dependence of product (lift/drag) $\max \times M$ on flight Mach number for aerospace system assembly

Therefore, it was this version of the aerospace system that was considered further as the main one (Fig. 11). The length of the aerospace system is $48.5 \mathrm{~m}$; the wingspan is $85 \mathrm{~m}$; the wheel track (by external wheels) is $27 \mathrm{~m}$.

In determining the aerodynamic characteristics of aerospace system assembly, the largest rocket system with oxygen-hydrogen first stage was considered as the main option. Due to the installation of the rocket system and the increase in the planned area, the lift coefficient of aerospace system assembly $C_{\mathrm{L}}$ increases somewhat, the drag coefficient $C_{\mathrm{D}}$ increases by $20-25 \%$. It is worth mentioning that not all aerodynamics were investigated yet (it is lack of return aerodynamic characteristics of both booster and shuttle).

Figure 12 shows the dependence of the product $\left(C_{\mathrm{L}} / C_{\mathrm{D}}\right)_{\max } \times M$ on the flight Mach number, from which it follows that the optimum cruise mode of the aerospace system as an assembly (excluding the characteristics of the jet engine) corresponds to Mach number $M \sim 0.65$.

The least unladen mass is 160 tons and corresponds to a perspective twin-fuselage subsonic carrier. From Table 1 it follows that the largest available masses of fuel have a perspective twin-fuselage carrier and twin-fuselage carrier based on M-60: 50.5 tons and 46 tons, respectively 
Table 1 Main mass breakdown table of subsonic carriers, $\mathrm{t}$

\begin{tabular}{llll}
\hline Parameters & \multicolumn{2}{l}{ Twin-fuselage } & \\
\cline { 2 - 4 } & Based on M-60 & Based on Il-76 & Perspective \\
\hline Dry mass & $178.91(51.4 \%)$ & $183.51(55.55 \%)$ & $157.02(47.53 \%)$ \\
Unladen mass & $182.09(53.74 \%)$ & $186.33(56.41 \%)$ & $159.85(48.39 \%)$ \\
Fuel mass, incl. reserve & $46(13.22 \%)$ & $24(7.27 \%)$ & $50.5(15.29 \%)$ \\
Payload mass & $120(34.47 \%)$ & $120(36.33 \%)$ & $120(36.33 \%)$ \\
MTOW & 348 & 330 & 330 \\
\hline
\end{tabular}

(including air navigation reserve) have the largest available fuel masses.

\section{Comparison of the three types of fuel of the rocket system first stage}

The choice of fuel plays a decisive role in designing the configuration of the orbital injection system. It is known that from the point of view of providing the greatest mass of payload at the last rocket stage the fuel with the highest specific impulse should be used. Therefore, the hydrogen-oxygen fuel is used on the shuttle. Three types of fuel-based on kerosene, liquid methane and liquid hydrogen (oxidizer is liquid oxygen) are considered for hypersonic booster. In solving this it was assumed that the aerospace system main design parameters were performed for launching cargo and crews into the low-earth orbit of $200 \mathrm{~km}$ height. By its energy such a flight is close to a low earth-orbit injection trajectory. The main optimization parameters:

- thrust-to-weight ratio of the rocket system stages;

- velocity of stage separation $V_{\text {sep}}$;

- trajectory parameters at the end of the shuttle active leg

As an optimization criterion the shuttle payload mass was used-the total mass of pressurized cabin module with the equipment, loading, crew and passengers; the number of the crew is 2 people. It was believed that for each person in addition to his own weight of $100 \mathrm{~kg}$ there are $350 \mathrm{~kg}$ of the average weight of equipped pressure cabin. The launching parameters of the rocket system and the conditions for the end of the active flight are the same.

Oxygen-hydrogen liquid rocket engine RD0146 developed by Voronezh JSC KBKhA [17] can be used as a prototype of booster $(\times 4)$ and shuttle $(\times 2)$ main engines, for booster-oxygen-methane RD0162 JSC KBKHA [18] and oxygen-kerosene RD191 JSC NPO Energomash [19]. The engines were scaled to maintain specific mass, specific thrust, and a specific impulse in the vacuum of the original engine.

The fuel change is accompanied by a change in the specific impulse of the liquid rocket engine, which increases by 1.05 times when changing kerosene for methane and by 1.38 when using hydrogen instead of kerosene. In addition, the volume of fuel varies. As a result, there is a redistribution of masses between the stages of the rocket system and the optimal speed of their separation changes. At the same time, the thrust-to-weight ratio of the stages also changes, which is in particular due to the dependence of the specific mass of the rocket engine on the type of fuel. All these factors lead to a change in mass of the injected payload. The main results of calculating the rocket system characteristics (excluding hypersonic booster return to take-off airfield) are listed in Table 2. In terms of the effect of overloads on the human body, all three options are almost identical.
Table 2 The main characteristics of the rocket system with three types of fuel

\begin{tabular}{llll}
\hline Parameters & Fuel types & & \\
\cline { 2 - 4 } & Kerosene $+\mathrm{O}_{2}$ & Methane $+\mathrm{O}_{2}$ & $\mathrm{H}_{2}+\mathrm{O}_{2}$ \\
\hline Booster fuel volume, $\mathrm{m}^{3}$ & 92.4 & 112.6 & 240.5 \\
Booster length $\times$ diameter, $\mathrm{m}$ & $17.85 \times 2.9$ & $19.05 \times 3.1$ & $24.47 \times 4$ \\
Rocket system length, m & 30.3 & 31.5 & 39.0 \\
Separation speed, m/s & 3700 & 3750 & 4100 \\
Rocket system thrust-to-weight ratio & 1.27 & 1.23 & 1.24 \\
Shuttle thrust-to-weight ratio & 0.9 & 0.89 & 0.97 \\
Shuttle mass, t & 17.76 & 17.76 & 20,87 \\
Payload mass, t & 2.21 & 2.27 & 3.17 \\
Crew + passengers & $2+3$ & $2+3$ & $2+5$ \\
\hline
\end{tabular}


Calculations showed that kerosene and methane variants of the booster are similar in their characteristics. As compared to methane variant the hydrogen booster makes it possible to simultaneously increase the rate of stage separation and the shuttle launching mass due to better fuel energy. In this case, the payload mass increases to 3.2 tons, which corresponds to a total number of 7 people ( 5 passengers and 2 crew members).

A general view of the rocket system with oxy-hydrogen hypersonic booster is presented in Fig. 13. The stages are connected by a truss structure. After the shuttle separation, the truss structure remains on the booster; one of the possible solutions is when truss members turn (the rods rotate) in hinged joints and are fixed along the surface of the fuselage.

\section{Rocket system stages}

When launching into orbit the motion control is performed using the rocket engine thrust vector. It is assumed, that each stage uses four engines installed in a cardan suspension. The rocket engine vacuum thrust of the booster is $37.2 \mathrm{t}$, of the shuttle is $5.0 \mathrm{t}$. Specific impulse of the rocket engine in a vacuum is $470 \mathrm{~s}$, which corresponds to the level of RD 0146 engine performance (KBKhA, Voronezh) [17].

The shuttle rocket engines have two-position nozzles. Immediately after the separation of the shuttle from hypersonic booster the nozzles are in the working position, and the engines are started; after the engine shut-off the nozzles are moved to the initial position. The option of installing two rocket engines on the shuttle is possible, in this case, the

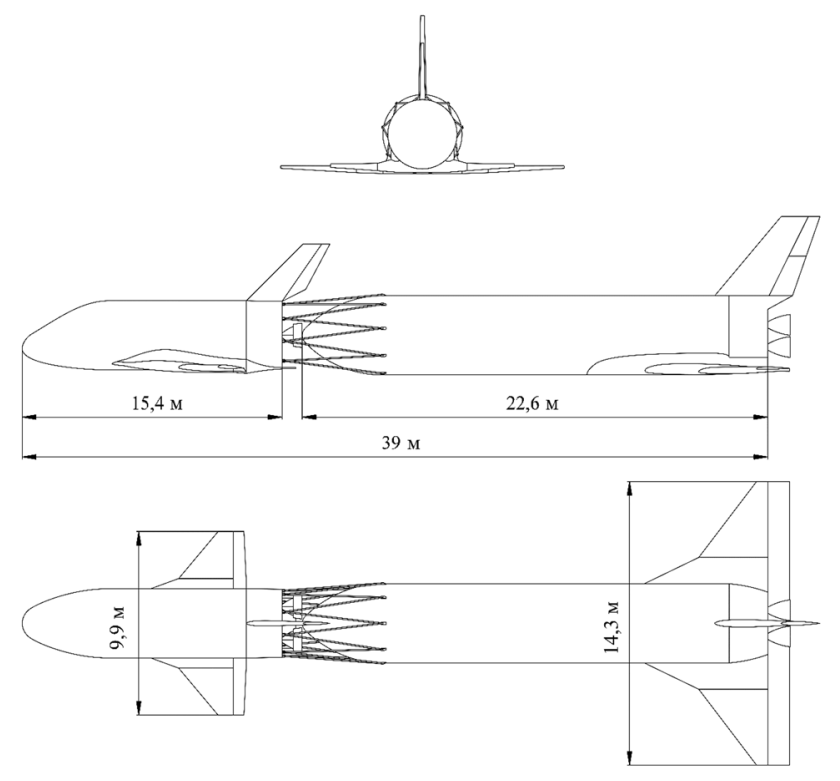

Fig. 13 The general view of the rocket system with oxy-hydrogen propulsion cruise engines thrust will be closer to RD 0146 engine. After disabling the rocket engines during super-aerodynamic flight, the hypersonic booster and the shuttle are controlled by a reactive system.

The hypersonic booster and the shuttle have "tailless" configuration with one fin and low wing. In the tail section of the booster and shuttle fuselage a balancing flap is installed. The booster and the shuttle fuselages have a circular cross section, tapered wings with leading-edge extension. The fuel tank with liquid oxygen is located in the front part of both the booster and the shuttle, the tank with fuel-behind the oxidizer tank. In this case, the maximum front centering of the rocket system is reached at the moment of its launch. The hypersonic booster is unmanned. The crew cabin and the passenger compartment of the shuttle are integral and located in the bow unit. The landing of both stages on the airfield is horizontal. Specific load of the booster and the shuttle at landing is $290-300 \mathrm{~kg} / \mathrm{m}^{2}$.

\subsection{Separation of the rocket system from the carrier}

The process of separating the rocket system from the twinfuselage carrier is calculated in view of its motion around the center of mass. It is assumed that the rocket system engines are started $3 \mathrm{~s}$ later after separation. During this time, the distance of the rocket system center of mass from the carrier is commensurable with the rocket system length. Since the rocket system is statically stable, the angle of attack in the first seconds after the drop is close to the initial value. After starting the rocket engine by means of thrust vector control the specified pitch angle control program begins to be developed. In this case, the angle of attack increases to $\sim 20^{\circ}$. The main requirement for the flight path of the carrier after aerospace system separation is its maximum distance from the rocket system. For this purpose, the carrier rolling motion is used. The maximum rate of the roll angle change was supposed to be $5 \%$, the maximum allowable angle of the roll is $30^{\circ}$. The angle of roll control begins immediately after the

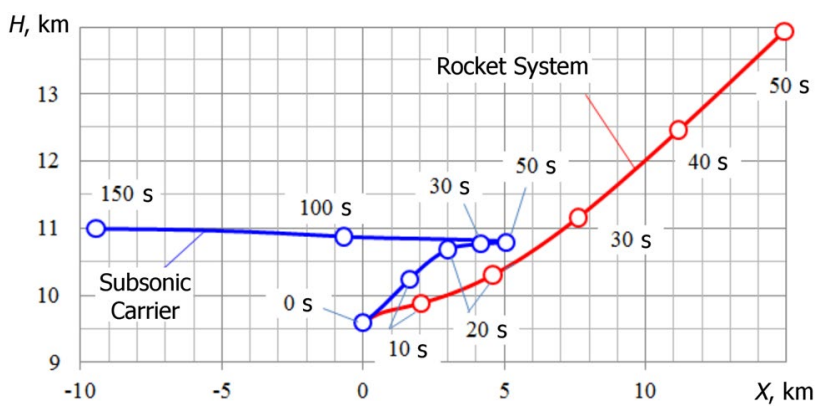

Fig. 14 Trajectories of rocket system injection and manoeuver of subsonic carrier, side view 


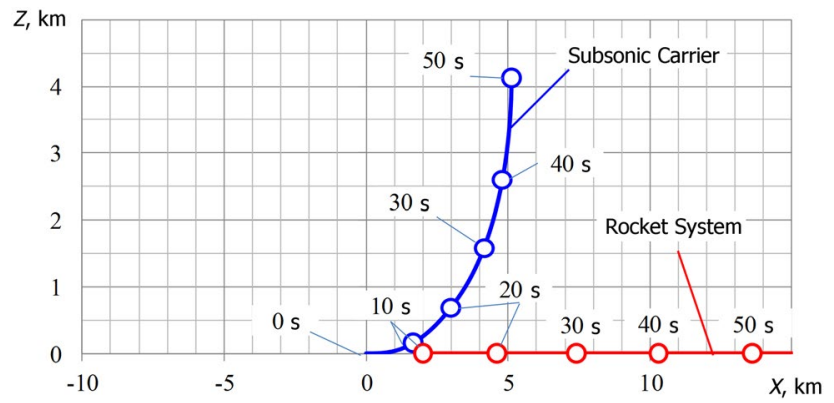

Fig. 15 Trajectories of rocket system injection and manoeuver of subsonic carrier in the earth surface projection

drop of the rocket system and ends after moving away from it for a sufficient distance.

The initial trajectory legs of the carrier and the rocket system (for one of the design variants) are presented in Figs. 14 and 15 . The points on the graphs show the attitude of the carrier and the rocket system after $10 \mathrm{~s}, 20 \mathrm{~s}$, etc. In $5 \mathrm{~s}$ after separation, the distance between the centers of mass of the carrier and the rocket system is $140 \mathrm{~m}$, in $10 \mathrm{~s}-340 \mathrm{~m}$, then the distance increases more and more.

\subsection{Trajectory of the rocket system injection}

In the calculation of trajectories, approximately optimal control of motion was used [20]. A sphere was used as a model of the Earth, the rotation of the Earth is not taken into account. Low earth orbit height is $200 \mathrm{~km}$. Initially, the rocket system version was considered with hypersonic booster landing along the flight path. At the point of the rocket system drop the trajectory parameters are:

velocity $V_{0}=189 \mathrm{~m} / \mathrm{s}\left(M_{0}=0.63\right)$;

altitude $H_{0}=9.59 \mathrm{~km}$;

trajectory angle $\theta_{0}=17^{\circ}$;

angle of attack $\alpha_{0}=3.4^{\circ}$.

The trajectory optimal parameters at the stage separation point are:

$V_{\text {sep }}=4100 \mathrm{~m} / \mathrm{s}(M \approx 15)$;

$H_{\text {sep }}=94.1 \mathrm{~km}$;

$\theta_{\text {sep }}=3.75^{\circ}$.

In Fig. 16 the trajectory of the active leg corresponding to the maximum of the launched payload mass is shown in the "altitude-velocity" coordinates, and the change in the current mass is also shown there.

The relative fuel supply of the first stage (relative to MTOW) is $67.6 \%$, the relative fuel supply of the second stage is $56.4 \%$.

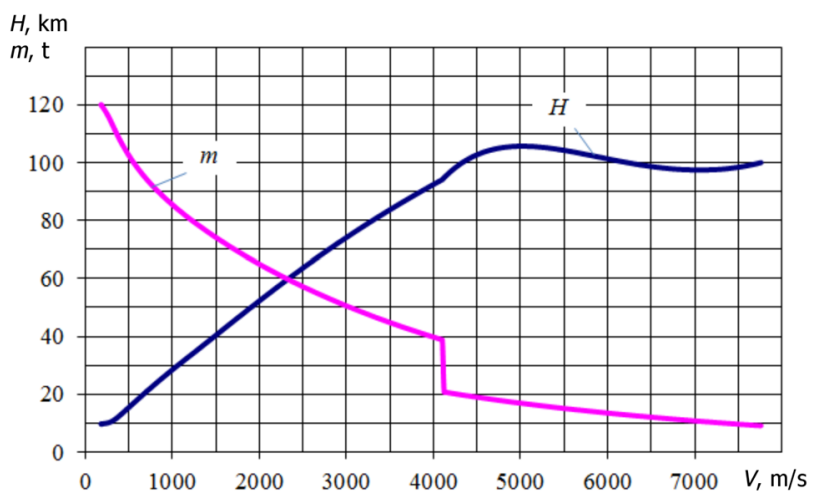

Fig. 16 Rocket system boost trajectory in "altitude-velocity" coordinates; change in mass by speed

\subsection{Descent of hypersonic booster}

When calculating the trajectory, it was assumed that the motion is without a roll at a constant angle of attack of $40-45^{\circ}$, which is close to the $C_{\mathrm{y} \text { max }}$ mode. This mode of the flight was chosen to maximize the drag force and reduce the flight range. The trajectory ended at subsonic velocity $V_{\text {final }}=300 \mathrm{~m} / \mathrm{s}$.

At optimum separation speed of $4100 \mathrm{~m} / \mathrm{s}$ the booster flight range is $1360 \mathrm{~km}$, the total range taking into consideration the initial flight leg of the rocket system is $1917 \mathrm{~km}$. This value slightly exceeds the operating range of the carrier. In this connection, two solutions are possible.

The first is an increase in the estimated range of the carrier by increasing its relative fuel supply. The second is the reduction in the rate of staging compared to the optimal price of some decrease in payload mass.

The second variant showed that the booster total flight range can be reduced to $\sim 1500 \mathrm{~km}$ if the rate of staging is reduced compared to the optimum one. Accordingly, the

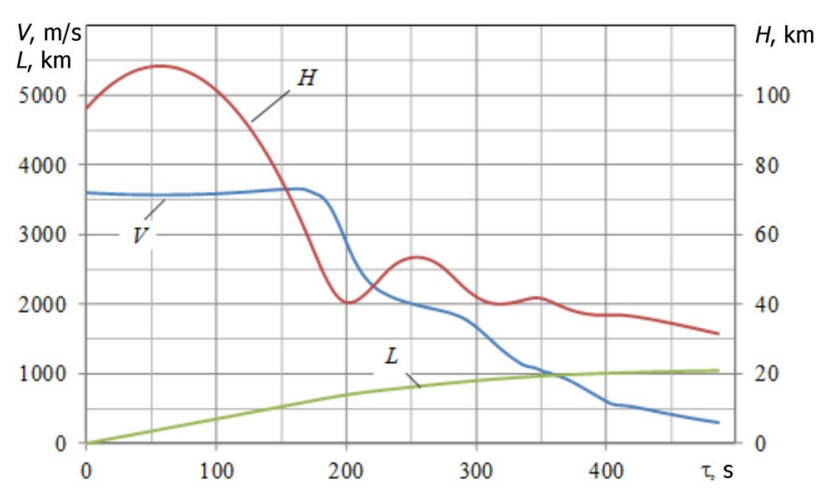

Fig. 17 Dependence of altitude, velocity and range on time of booster return flight $\left(V_{\text {sep }}=3.6 \mathrm{~km} / \mathrm{s}\right)$ 
trajectory of the rocket system injection was recalculated. In this case, the parameters of stage separation are:

$V_{\text {sep }}=3600 \mathrm{~m} / \mathrm{s}(M \approx 13)$;

$H_{\text {sep }}=96.3 \mathrm{~km}$;

$\theta_{\text {sep }}=6.81^{\circ}$;

range $L_{\text {sep }}=450 \mathrm{~km}$.

The passive flight path of the booster is presented in Fig. 17. The time of the booster passive flight is $486 \mathrm{~s}$, the total flight range including the initial leg with the rocket system is $1495 \mathrm{~km}$.

In contrast to the shuttle, the booster flight path at the initial stage of passive motion differs greatly from the quasistationary one, which leads to a more pronounced oscillatory character. The maximum normal overload is 4.1 , while the dynamic pressure is $1200 \mathrm{~kg} /\left(\mathrm{m} \times \mathrm{s}^{2}\right)$. Trajectory variations take place during the first period and a half, at a speed of $\sim 1700 \mathrm{~m} / \mathrm{s}$ the trajectory approaches the quasistationary one.

Due to decrease in the speed $V_{\text {sep }}$ as compared to the optimal speed calculated without taking into account the booster return to the point of aerospace system take-off, the payload mass decreased by $\sim 95 \mathrm{~kg}$, that is $\sim 3 \%$ (launching payload into orbit height of $200 \mathrm{~km}$ ). Thus, it can be concluded that the condition for the return of the first stage to the starting point virtually does not lead to a deterioration in the rocket system characteristics. In prospect, it is necessary to investigate flight safety considerations.

\section{Conclusions}

The method has been created that combines the modules of geometric parameters, aerodynamics, engine characteristics, flight data, mass and cost values to study the aerospace system.

The method of launching the shuttle into orbit is proposed, which allows for the return of the carrier aircraft and the booster to the launch airfield. The aerospace system is flown to a predetermined location (about $1500 \mathrm{~km}$ from the aerodrome), then it U-turns and launches the rocket system.

The results of the analysis of the three variants of the carrier aircraft showed that the flight performance of the perspective twin-fuselage subsonic carrier is significantly better due to the smaller fuselage mid-section area and lower dry mass.

Depending on the type of booster fuel, the specific cost of launching into orbit differs by no more than $10 \%$. Thus, when choosing the type of fuel for an aerospace system, it is necessary first of all to be guided by technical indicators (payload mass, flight range), environmental indicators, flight safety, etc.
Open Access This article is licensed under a Creative Commons Attribution 4.0 International License, which permits use, sharing, adaptation, distribution and reproduction in any medium or format, as long as you give appropriate credit to the original author(s) and the source, provide a link to the Creative Commons licence, and indicate if changes were made. The images or other third party material in this article are included in the article's Creative Commons licence, unless indicated otherwise in a credit line to the material. If material is not included in the article's Creative Commons licence and your intended use is not permitted by statutory regulation or exceeds the permitted use, you will need to obtain permission directly from the copyright holder. To view a copy of this licence, visit http://creativecommons.org/licenses/by/4.0/.

\section{References}

1. Osnovy politiki Rossijskoj Federacii v oblasti kosmicheskoj deyatel'nosti do 2030 goda i na dal'nejshuyu perspektivu. Federal'nyj spravochnik Rossijskoj Federacii [Fundamentals of the Russian Federation's policy in the field of space activities until 2030 and for the future. Federal directory of the Russian Federation]. 2013 URL: http://federalbook.ru/files/OPK/Soder janie/OPK-11/V/Osnovnie\%20pologeniya.pdf. Accessed 25 Jun 2019

2. Lozino-Lozinskiy G. Ye.: Polet "Burana"//Gagarinskie nauchnye chteniya po kosmonavtike i aviatsii 1989 [Flight of "Buran"//Gagarin scientific readings on astronautics and aviation 1989], М.: Наука, 1990. p. 6-21.

3. Space Shuttle News Reference Manual. 1988. p. 924. http:// science.ksc.nasa.gov/shuttle/technology/sts-newsref/stsref-toc. html. Accessed 17 Jul 2018

4. MAKS razdel: sostoyanie razrabotki, nauchno-tekhnichesky zadel//Entsiklopediya Buran. [MAKS section: development status, scientific and technical // Encyclopedia Buran. http:// buran.ru/htm/makszad.htm. Accessed 17 Jul 2018

5. Kuzin, A.I., Vakhnichenko, V.V., Lozin, S.N., Lekhov, P.A., Semenov, A.I., Gorbatenko, V.V., Romashkin, A.M.,Buzuluk, V.I., Plokhikh, V.P., Kovalev, I. Ye., Tsyplakov, V.V., Kondratov, A.A.: Mnogorazovaya raketno-kosmicheskaya sistema. Blizhaishiye perspectivy rasrabotki i letno-eksperimentalnoi otrabotki Nauchno-tekhnichesky zhurnal "Aviakosmicheskaya tekhnika I tekhnologiya" [Reusable rocket-space system. Nearterm prospects of development and flight experiment. Sci. Tech. J. Aerosp. Eng. Technol. 2, 9-18 (2010)

6. Plokhikh, V.P., Buzuluk, V.I., Udzhukhu, A. Yu.: High-speed aircraft of intercontinental and global range of flight//Nauka i tekhnologii v promyshlennosti. 1 (1), 92-100 (2012)

7. Mikhalyov, S.M.: Trudy MAI, 2015, iss. 81. http://www.mai.ru/ science/trudy/published.php?ID=57706. Accessed 25 Jul 2018

8. Mikhalyov, S.M.: The method of forming the shape of a reusable aerospace system based on twin-fuselage carrier, optimization of its design parameters and motion paths: thesis for a $\mathrm{PhD}$ in Engneering sciences. Moscow, 2019, 155 p. https://rusneb.ru/ catalog/000199_000009_008585898/. Accessed 1 May 2020

9. Buzuluk, V.I., Mikhalyov, S.M.: Development of the method of forming the shape of a reusable aerospace system, optimization of its design parameters and motion paths//Nauchno-tekhnichesky zhurnal. "Nauka I Innovatsii", 6. https://doi.org/10.18698 /2308-6033-2019-6-1894 (2019)

10. Buzuluk, V.I., Mikhalyov, S.M.: Optimization of Aerospace System Parameters Using CFD Simulation//Nauchno-tekhnichesky zhurnal. "Nauka I Innovatsii", 2017(9) https://doi.org/10.18698 /2308-6033-2017-9-1668. Accessed 4 Dec 2018 
11. Buzuluk, V.I., Vasilev, R.P., Voevodenko, N.V., Gubanov, A.A., Gurevich, B.I., Talyzin, V.A., Chernyshev, S.L.: Issledovaniya kontseptsiy vysokoskorostnykh grazhdanskikh samoletov v TsAGI, Obshcherossiysky nauchno-tekhnichesky zhurnal "Polet" [Analysis of high-speed civil aircraft concepts in TsAGI, All-Russian scientific and technical journal "Flight"] 11, 37-49 (2018)

12. Steelant, J., Langener, T.: The LAPCAT-MR2 Hypersonic Cruiser Concept. ICAS-2014-0428. 29th Congress of the International Council of the Aeronautical Sciences, St. Petersburg, Russia, September 7-12, 2014

13. Lozino-Lozinskiy, G. Ye., Bratukhin, A.G., ed. Aviatsionnokosmicheskiye sistemy [Aerospace systems]. Moscow, MAI Publ., p. 416 (1997)

14. Foust, J.: NASA agreement sign of Stratolaunch engine development program. Space News, 15 November 2017

15. Shkadov, L., Denisov, V., Lazarev, V., Plokhikh, V., Buzuluk, V., Volodin, S., Chervonenko, K., Skipenko, V.: The comparative analysis of various aerospace system concepts. Acta Astronaut. 35(1), 47-54 (1995)

16. Udzhuhu, A., Evstifeev, V., Lazarev, V., et al.: Automated computational dialogue system (ARDIS). Certificate of state registration of the computer program No. 2010611209. Registered on 11.02 .2010

17. RD0146D. Official site of Khimavtomatika Design Bureau JSC. http://www.kbkha.ru/?p=8\&cat $=8 \&$ prod=73. Accessed 4 Dec 2019

18. RD0162SD Official site of Khimavtomatika Design Bureau JSC. http://www.kbkha.ru/?p=8\&cat=8\&prod=59. Accessed 4 Dec 2019

19. Universal rocket engine RD191. Prospect data. Site of VPK news. https://vpk.name/library/f/rd-191.html. Accessed 7 Nov 2020

20. Buzuluk V.I.: Optimizatsiya trayektorii dvizheniya aerokosmicheskikh letatelnykh apparatov [Optimizing the movement trajectory of aerospace flying vehicles]. Moscow, TsAGI Publ., p. 476 (2008)

Publisher's Note Springer Nature remains neutral with regard to jurisdictional claims in published maps and institutional affiliations. 